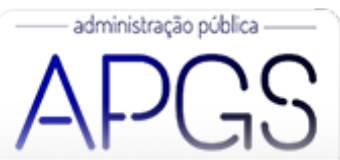

Administração Pública e Gestão Social ISSN: 2175-5787

apgs@ufv.br

Universidade Federal de Viçosa

Brasil

\title{
Cocriação de Valor em Programas Empresariais de Marketing Social: uma análise multicaso
}

\author{
Albino, Andréia Aparecida; Grubits de Paula Pessôa, Luís Alexandre \\ Cocriação de Valor em Programas Empresariais de Marketing Social: uma análise multicaso \\ Administração Pública e Gestão Social, vol. 11, núm. 2, 2019 \\ Universidade Federal de Viçosa, Brasil \\ Disponível em: http://www.redalyc.org/articulo.oa?id=351558326003
}

Esta obra está bajo una Licencia Creative Commons Atribución-NoComercial-SinDerivar 3.0 Internacional. 


\title{
Cocriação de Valor em Programas Empresariais de Marketing Social: uma análise multicaso
}

\author{
Co-creation of value in social marketing business initiatives: A multi-case study \\ Co-creación de valor en programas empresariales de marketing social: un análisis multicaso
}

Andréia Aparecida Albino

Instituto Federal do Sudeste de Minas Gerais - Campus Rio

Redalyc: http://www.redalyc.org/articulo.oa?

Pomba, Brasil

andreia.albino@ifsudestemg.edu.br

Luis Alexandre Grubits de Paula Pessôa

Pontifícia Universidade Católica do Rio de Janeiro, Brasil

lpessoa@iag.puc-rio.br

Recepção: 07 Novembro 2016

Aprovação: 08 Janeiro 2018

Publicado: 01 Abril 2019

\section{Resumo:}

Considerando o potencial do marketing social e o advento da lógica de serviço, este estudo multicaso buscou identificar, na perspectiva dos atores envolvidos, em especial o público pretendido, como a cocriação de valor é abordada nos programas de marketing social desenvolvidos por uma empresa privada, em parceria com outras organizações no Brasil. Foram estudadas três iniciativas que abrangiam causas de interesse da sociedade: separação de resíduos sólidos, cuidados com a saúde cardiovascular e hábitos de higiene, especialmente a lavagem das mãos. A coleta de dados envolveu quarenta entrevistas realizadas pessoalmente, observação e consulta a arquivos e documentos, utilizando a análise qualitativa. Identificou-se que as iniciativas estudadas contemplam diversos elementos da cocriação de valor, sendo a abordagem mais evidente a downstream, voltada à mudança do comportamento individual. Além de indicar aspectos para aperfeiçoar as ações, o estudo colabora para a operacionalização do conceito de cocriação de valor no marketing social.

Palavras-chave: Marketing Social, Cocriação de Valor, Lógica de Serviço.

\section{Abstract:}

Considering the potential of social marketing and the emergence of service dominant logic, this multi case study aims to identify, from the actors' perspectives, especially the target audience, how the co-creation of value is addressed in social marketing projects developed by a private company in partnership with other organizations in Brazil. Three initiatives that covered areas of public interest were studied: separation of solid residues, cardiovascular health care and hygiene habits, especially hand washing. The data collection took place through forty personal interviews, observation, examination of files and documents, in a qualitative analysis. It was found that the studied initiatives feature the co-creation of many value elements, and the downstream approach is more inclined towards the change of individual behavior. . Apart from identifying aspects to improve procedures, the study cooperates with the operationalization of the co-creation of value concept in social marketing.

KEYWORDS: Social marketing, co-creation of value, service dominant logic.

\section{RESUMEN:}

Considerando el potencial del marketing social y el avance de la lógica del servicio, este estudio multicaso buscó identificar, en la perspectiva de los actores involucrados, en especial la audiencia, como la co-creación de valor es abordada en los programas de marketing social desarrollados por una empresa privada en asociación con otras organizaciones en Brasil. Hubimos estudiado tres iniciativas que abarcaban causas de interés de la sociedad: separación de residuos sólidos, cuidado con la salud cardiovascular y hábitos de higiene, especialmente el aseo de las manos. La coleta de datos involucró cuarenta entrevistas, observación, consulta a archivos y documentos. El análisis fue cualitativa. Se señaló que las iniciativas estudiadas contemplan diversos elementos de la co-creación de valor, siendo el enfoque más evidente el downstream, vuelta al cambio del comportamiento individual. Además de direccionar aspectos para perfeccionar las acciones, la investigación colabora para la operación del concepto de co-creación de valor en marketing social. 
Palabras clave: Marketing social, co-creación de valor, lógica de servicio.

\section{INTRODUÇÃO}

Tradicionalmente associado a programas advindos do setor público ou de organizações sem fins lucrativos, o marketing social recentemente passou também a ser visto como meio para que as empresas possam intervir na sociedade, exercitando sua responsabilidade social. Isso ocorre porque "as empresas passaram a ter clara consciência de que devem devolver algo de significativo às comunidades em que atuam" (Costa \& Matos, 2009, p. 69), de modo que não só o setor público seja responsabilizado pelo bem-estar da coletividade.

O campo do marketing social representa uma abordagem promissora para transformar determinados aspectos sociais e pode ser conceituado, de maneira resumida, como a aplicação de ferramentas do marketing tradicional com o objetivo de alterar o comportamento do público em benefício da sociedade (Andreasen, 2003) ou, em linhas mais amplas, de promover a transformação social (Saunders, Barrington \& Sridharan, 2015).

A literatura sobre marketing social é vasta e uma das abordagens mais recentes indica que a perspectiva da lógica de serviço - abordagem defendida na última década por autores que se desvincularam da noção de agregação de valor apenas por parte das organizações - pode contribuir para o desenvolvimento desse campo de estudos (Lefebvre, 2012; Vargo \& Lusch, 2004). Esta abordagem tem recebido destaque na literatura, evidenciando que o valor, em vez de ser agregado a produtos e serviços pelas organizações, é criado em conjunto com os consumidores, situação conhecida como cocriação de valor (Ranjan \& Read, 2014; Vargo \& Lusch, 2004), entendida como um conceito abrangente que descreve a colaboração entre as partes envolvidas para perseguir um objetivo, sendo, segundo Ranjan e Read (2014), embasada na coprodução (constituída pelo compartilhamento de conhecimentos, equidade e interação) e no valor de uso (constituído pela experiência, relacionamento e personalização).

A lógica de serviço e, consequentemente, a da cocriação de valor, mesmo sendo conceitos que ainda se encontram em fase de refinamento, aparentemente deslocam o eixo pelo qual se analisa a teoria do marketing e, neste sentido, diversos autores passaram a conjecturar que o marketing social poderia ser beneficiado pelas suas pressuposições, uma vez que depende de forte envolvimento do público para obter resultados satisfatórios, sendo esse envolvimento uma importante característica da lógica de serviço. Entretanto, apesar de a literatura sobre marketing social ser considerada abrangente, não foi identificada, até o momento, nenhuma pesquisa que mostre a percepção do público e dos parceiros envolvidos a respeito de como as empresas brasileiras e organizações parceiras que desenvolvem programas de marketing social utilizam o conceito de cocriação de valor. Apesar de existirem artigos que discutem o marketing social à luz dessa noção , isso é feito de maneira predominantemente conceitual (Desai, 2009; Domegan, Collins, Stead, McHugh \& Hughes, 2013; Lefebvre, 2012; Russell-Bennett, Previte \& Zainuddin, 2009; Russell-Bennett, Wood \& Previte, 2013) e, nos raros casos em que se identificam pesquisas que relacionaram os dois temas, estas foram realizadas tendo por objeto de estudo programas desenvolvidos exclusivamente no âmbito da administração pública (Zainuddin, 2013), cuja lógica de atuação difere da lógica do setor privado. Fortalecendo a importância desse tipo de pesquisa, Dietrich et al. (2016) defendem que a investigação relacionada com o processo de cocriação em marketing social é ainda limitada, seja para o caso de programas do setor público, seja do setor privado.

Uma vez que a literatura identificada apresenta abordagens conceituais acerca dos temas citados e que alguns artigos até ressaltam que as propostas carecem de aprimoramento (Lefebvre, 2012), considerou-se oportuno desenvolver um estudo empírico que busque responder ao seguinte questionamento: de que modo o público pretendido e os parceiros percebem os programas de marketing social desenvolvidos por uma empresa privada no Brasil, em relação ao conceito de cocriação de valor? Tendo como referência as lacunas 
identificadas quando da revisão de literatura e visando ao aprofundamento no problema proposto, a presente pesquisa também perseguiu os seguintes questionamentos intermediários: i) quais elementos da lógica de serviço se fazem presentes nos programas de marketing social desenvolvidos por uma empresa no Brasil?; ii) que tipo de interação se faz mais presente nesses programas?; iii) de que maneira são desenvolvidos os processos de descoberta, design e entrega de valor em programas de marketing social desenvolvidos por uma empresa no Brasil?; e iv) que abordagens têm sido mais exploradas em projetos de marketing social desenvolvidos por uma empresa privada no Brasil?

Em resumo, o principal objetivo desta pesquisa foi identificar, na perspectiva do público e de organizações parceiras, como a cocriação de valor é abordada e se manifesta nos programas de marketing social desenvolvidos por uma empresa privada no Brasil, em parceria com organizações de procedências diversas. Para tanto, foi feito um estudo multicaso, de abordagem qualitativa, que analisou, por meio de entrevistas, observação e consulta a documentos, ações que integram um projeto da Empresa X em parceria com entidades do setor privado e com organizações sem finalidade lucrativa.

Este artigo está organizado da seguinte maneira: além desta introdução, o próximo tópico apresenta a revisão de literatura sobre a lógica de serviço, cocriação de valor e marketing social. Em seguida, são apresentados os procedimentos metodológicos do estudo, seguidos dos resultados, considerações finais e recomendações para pesquisas futuras.

\section{Fundamentos TEÓRICOS: LÓGICA DO SERVIÇO}

Shostack (1977) levantou questionamentos sobre a possibilidade de produtos prestarem algum tipo de serviço. Inclinados a pensar como Shostack, Vargo e Lusch (2004) foram os primeiros a discutir uma nova lógica para o campo do marketing, mais centrada no papel dos serviços do que no paradigma dos bens. Para tanto, definiram serviço como "a aplicação das competências (conhecimento e habilidades) por meio de ações, processos e performance em benefício de si próprio ou de outra entidade” (Vargo \& Lusch, 2004, p. 2). Os referidos autores postulam que a lógica centrada no serviço representa uma reorientação filosófica, que se aplica a todo tipo de oferta de marketing, inclusive às que envolvem bens físicos no processo de prestação de serviços. Para Lusch e Vargo (2012, p. 194), "os serviços podem ser fornecidos diretamente por pessoas prestadoras de serviços ou, de maneira indireta, por meio de bens".

A lógica de serviço pressupõe que as organizações podem colaborar e aprender com os clientes, adaptando-se às suas necessidades, sendo, portanto, "definidas pela cocriação com o consumidor, ao invés da incorporação de valor nos outputs" (Vargo \& Lusch, 2004, p. 6). Preconiza-se que o conceito de "valor de uso" se adapta melhor à realidade, afastando-se do conceito de "valor de troca", tradicionalmente defendido no campo do marketing.

O valor de troca admite que um produto ou serviço será trocado com o cliente por algo que para ele tenha valor (uma quantia ou algum sacrifício não monetário, por exemplo) (Bowman \& Ambrosini, 2000; Vargo, Maglio \& Akaka, 2008).É de acordo com tal premissa que se firmou a noção de que uma empresa agrega valor pela adição de propriedades ao produto. Já o valor de uso, que ocorre por um processo contínuo, envolve e "enfatiza as experiências do cliente" (Grönroos \& Voima, 2013, p. 135), requerendo que ele utilize o produto, pois, conforme identificado por Ranjan (2014), o valor é criado sempre em uso. Em outras palavras, ele é determinado pelo cliente com base na utilização de algo (Higuchi \& Veiga, 2015; Ranjan \& Read, 2014; Vargo \& Lusch, 2004).

Diversos autores, inclusive os proponentes da lógica de serviço, contribuíram para o seu refinamento. Vargo e Lusch (2016) apresentam as premissas da lógica de serviço da forma como tem sido articulada atualmente[i]

i. O serviço é a base fundamental da troca (status de axioma); 
ii. A troca indireta mascara a unidade fundamental de troca;

iii. Os bens são mecanismos de distribuição para a prestação de serviços;

iv. Recursos operantes são a fonte fundamental de benefícios estratégicos;

v. Todas as economias são economias de serviços;

vi. Valor é cocriado por múltiplos atores, sempre incluindo o beneficiário (status de axioma);

vii. Atores não podem entregar valor, mas podem participar da criação e da oferta das proposições de valor;

viii. Uma visão centrada em serviço é orientada para o beneficiário e relacional;

ix. Todos os atores sociais e econômicos são integradores de recursos;

x. O valor é sempre único e fenomenologicamente determinado pelo beneficiário (status de axioma);

xi. O valor é coordenado por instituições baseadas nos atores e arranjos institucionais (status de axioma).

\section{Cocriação de VALOR}

Um dos elementos que sustentam a lógica de serviço é a cocriação de valor, que traz o valor de uso e a maior participação do público no processo de criação de valor como elementos norteadores (Ranjan \& Read, 2014; Vargo \& Lusch, 2004, 2008).

Ranjan e Read (2014) analisaram a literatura sobre cocriação de valor para verificar se o conceito era adequadamente utilizado pelos autores e identificaram dois elementos fundamentais que a embasam: a coprodução e o valor de uso. No que diz respeito à coprodução, os autores identificaram as seguintes dimensões subjacentes à cocriação de valor:

$\$$ Compartilhamento de conhecimentos: consiste em os consumidores partilharem ideias, criatividade, experiências e conhecimentos com as organizações;

$\S$ Equidade: conjunto que envolve a disposição da organização em compartilhar o controle em favor dos consumidores e o desejo do consumidor de contribuir com as atividades de cocriação;

$\$$ Interação: entendida como a principal interface entre as partes envolvidas na coprodução.

Além disso, Ranjan e Read (2014) também identificaram três dimensões subjacentes ao valor de uso, a saber:

$\S$ Experiência: interação empática e emocional que se manifesta sob a forma de processos cognitivos e afetivos e gera valor de uso ao oferecer uma sensação de autotransformação;

$\S$ Relacionamento: processos interativos, recíprocos e conjuntos que são a base do relacionamento em um ambiente ativo de comunicação e engajamento;

$\S$ Personalização: refere-se à singularidade do processo de uso real ou percebido, sendo dependente de características individuais.

Bharti et al. (2015), por sua vez, revisaram o tema, visando a conceituar o processo de cocriação de valor e mostrar seus elementos, tendo identificado 26 deles, que foram organizados em cinco pilares (Figura 1). 


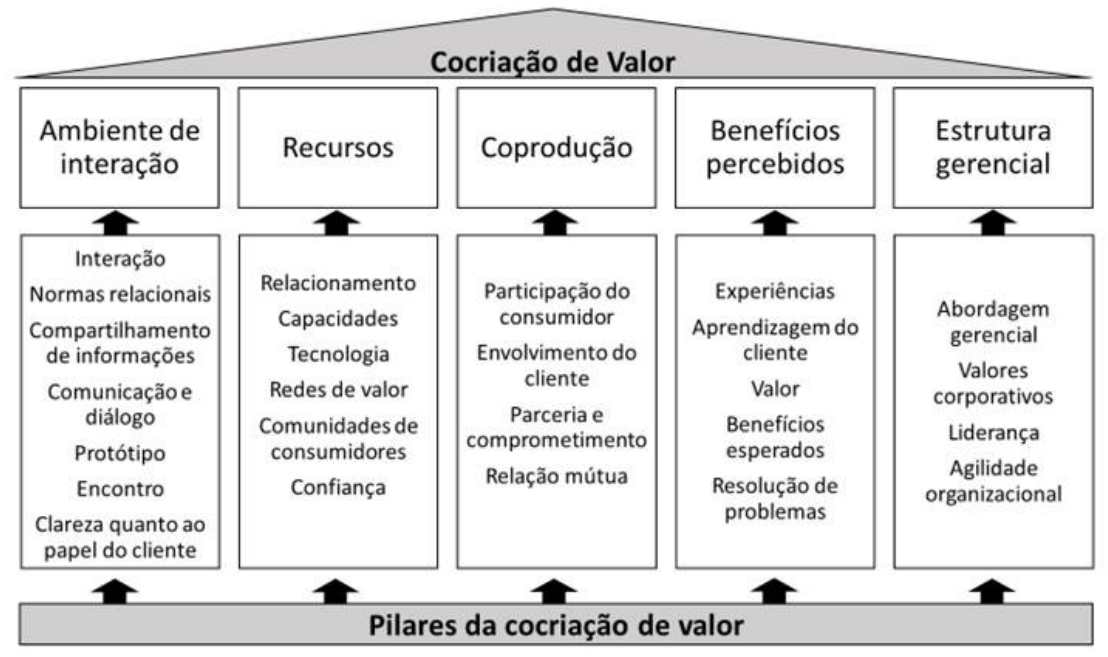

Figura 1: Pilares da cocriação de valor.

Fonte: Adaptado de Bharti et al. (2015, p. 584).

Bharti et al. (2015) explicam que o modelo proposto envolve um forte aspecto de interdependência de suas partes, uma vez que, para que se possa afirmar que a cocriação de valor é desenvolvida no âmbito de uma organização, não basta que um pilar se faça presente, pois, se assim for, há o risco de não serem atingidos os objetivos esperados. Há, portanto, complementaridade entre as partes do modelo e elas só fazem sentido umas em relação às outras.

\section{MARKETING SOCIAL}

Kotler (1972) argumentou que uma noção abrangente de marketing envolve, também, mas não somente, as tentativas de influenciar pessoas a fazer determinadas coisas, como abandonar um hábito prejudicial à saúde, que prejudique a sociedade como um todo ou, ainda, criar novos hábitos. Uma definição amplamente utilizada de marketing social é apresentada por Andreasen (2003, p. 5), que afirma que esse conceito consiste na

aplicação das várias tecnologias utilizadas no marketing comercial para analisar, planejar, executar e avaliar programas projetados com o objetivo de influenciar o comportamento voluntário de públicos-alvo a fim de melhorar seu bem-estar pessoal e da sociedade (Andreasen, 2003, p. 5).

Como existem algumas críticas a essa definição, já que se questiona, por exemplo, a voluntariedade da mudança de comportamento, entre outros aspectos, algumas associações de marketing social procuraram atingir um consenso sobre a definição que melhor representaria o marketing social. Assim, foi proposta a seguinte definição:

Marketing social visa a desenvolver e integrar conceitos de marketing com outras abordagens para influenciar comportamentos que beneficiam os indivíduos e as comunidades para o maior bem social. A prática do marketing social é orientada por princípios éticos. Procura integrar pesquisa, melhores práticas, teoria, público e percepção de parcerias para inspirar uma forma flexível de competição, bem como programas segmentados de mudanças sociais que são eficazes, eficientes, equitativos e sustentáveis (iSMA, ESMA, AASM, 2013).

O marketing social pode manifestar-se segundo diferentes abordagens: downstream, upstream e midstream. A primeira tem seu foco nos públicos, que apresentam ou que poderiam apresentar comportamentos sociais indesejáveis e foi uma das primeiras abordagens relacionadas ao marketing social, recebendo algumas críticas por ser considerada uma abordagem que atribui muita responsabilidade ao 
público. A segunda pressupõe que o marketing social deve concentrar-se em estimular modificações nos fatores que atuam em níveis mais básicos da formação do comportamento das pessoas, como a ação da iniciativa privada, autoridades em geral ou a legislação (Andreasen, 2006; Carvalho \& Mazzon, 2015; Stead, Gordon, Angus, \& McDermott, 2007; Truong, 2014). Considerando a insuficiência da abordagem dowstream, Andreasen (2006) afirmou, em seus trabalhos mais recentes, que a abordagem upstream tem muito a contribuir para melhorias na sociedade, e alguns autores consideram que mesclar as duas pode trazer resultados mais robustos para os programas de marketing social (Khajeh, Dabestani \& Fathi, 2015) . A terceira abordagem pressupõe que a experiência de serviços, os colaboradores do setor de serviços, a qualidade do atendimento prestado e o papel ativo do público pretendido na criação de valor têm condições de influenciar e apoiar os objetivos de mudança de comportamento individual.

Andreasen (2006) defende que o foco do marketing social é o de influenciar comportamentos de um modo geral, ou seja, além dos comportamentos que deliberadamente são vistos como prejudiciais à sociedade, o marketing social tem boas condições para influenciar na criação de novos comportamentos.

Andreasen (2002, p. 7) propôs alguns critérios que ajudam a identificar ações de marketing social e explica que os programas não necessariamente precisam conter todos esses critérios para serem caracterizados como programas de marketing social. Os critérios são os seguintes:

$\S$ A mudança de comportamento deve ser a referência central a ser utilizada para projetar e avaliar as intervenções;

$\S$ Os projetos desenvolvem pesquisas com o público pretendido para compreendê-lo desde o início das intervenções, identificar aspectos relevantes da intervenção antes de sua implementação e monitorar as intervenções;

$\S$ Leva-se em conta a segmentação desse público como forma de aumentar as chances de as intervenções serem bem-sucedidas;

$\S$ As estratégias de influência procuram tornar as trocas atraentes, motivando o público;

$\S$ A estratégia procura utilizar todos os elementos do marketing mix para atingir seus objetivos;

$\S$ A concorrência é considerada quando da elaboração dos programas.

Existem diversas especificidades que tornam o marketing social diferente e, por vezes, mais desafiador do que marketing do setor comercial. Assim, o mix de marketing social também foi alvo de discussões e aprimoramentos para que se tornasse mais condizente com tais especificidades. Autores como Kotler e Lee (2011) e Madill e Ziegler (2012) levam em conta os primeiros elementos que constituíram o mix de marketing, enquanto Weinreich (2011) promove alguns acréscimos ao mix, considerando também a importância dos públicos, das parcerias, da política e das fontes de recursos. Gordon (2012), por sua vez, defende que o marketing mix necessita passar por reformulações que considerem tanto a complexidade das atuais relações entre os atores envolvidos com o marketing social quanto a incorporação de elementos presentes em abordagens não provenientes da área de marketing, mas que igualmente contribuem para a prática do marketing social. $\mathrm{O}$ referido autor argumenta que muitos profissionais que atuam no campo de marketing social não advêm da área de marketing e que suas perspectivas devem ser, de algum modo, incorporadas ao marketing mix.

\section{Procedimentos Metodológicos}

Este estudo multicaso tem finalidade exploratória, uma vez que há pouco conhecimento empírico que associe os temas de interesse desta pesquisa. A abordagem qualitativa foi a que melhor se ajustou aos objetivos desta pesquisa. A seleção das iniciativas estudadas foi embasada nos seguintes critérios: i) mostrar indicativos de mudança de comportamento; ii) envolver assuntos de reconhecida relevância para a sociedade; iii) ter considerável abrangência, atendendo e mobilizando grande número de pessoas; e iv) advir de organizaçóes 
que oferecem riqueza de informações documentais divulgadas em fontes de livre acesso. Diante disso, identificou-se como objeto de estudo um recorte do projeto KLZ, desenvolvido pela Empresa X, que possui várias iniciativas, que, por sua vez, tem parceiros específicos. Foram investigadas as seguintes ações vinculadas aos projetos:

$\S$ Iniciativa 1, que, em parceria como o Grupo Empresarial Y, busca destinar adequadamente resíduos sólidos;

$\S$ Iniciativa 2, que visa a estimular o hábito de lavar as mãos como forma de evitar doenças, em parceria com a ONG K e com o Ministério da Saúde;

$\S$ Iniciativa 3, que visa a incentivar atitudes que contribuam para a boa saúde cardíaca, tendo como parceiro o Hospital L .

A Iniciativa 1 busca implantar estações de recolhimento de materiais recicláveis nas lojas do Grupo Empresarial Y e, de acordo com o site do projeto KLZ , 126 estações de coleta estão distribuídas em oito estados brasileiros, além do Distrito Federal. Nos chamados Pontos de Entrega Voluntária (PEV), que ficam nos estacionamentos das lojas do Grupo Empresarial Y, o consumidor pode descartar materiais diversos, como vidro, plástico, papel, metal e óleo de cozinha, além de embalagens aerossóis, estas últimas recolhidas apenas em alguns pontos de coleta. Todo o material recolhido é doado a várias cooperativas de reciclagem, gerando emprego e renda e evitando que tais resíduos tenham um descarte inadequado.

A Iniciativa 2 procura disseminar práticas de higiene entre o público-infantil, especialmente em relação à lavagem das mãos. A marca de sabonetes $S$ está vinculada à ideia e tem como parceira à ONG K. Os seguintes passos fazem parte da iniciativa: i) conscientização, na qual é carimbada uma imagem de uma bactéria nas mãos das crianças e depois os voluntários lavam as mãos dessas crianças para que elas percebam que a figura carimbada desaparece; ii) entrega da cartilha com 21 passos para criar o hábito de lavar as mãos em casa; iii) compromisso assumido pelas crianças de desenvolverem as atividades previstas perante o voluntário da ONG $\mathrm{K}$; iv) para a construção do hábito propriamente dita, as pessoas deverão realizar as atividades relacionadas à lavagem das mãos durante 21 dias; e v) reconhecimento das crianças e das famílias que executaram o programa, feito pela entrega de um adesivo em formato de mão, no qual a criança é parabenizada pelo cumprimento das atividades.

A Iniciativa 3 procura incentivar a troca de experiências sobre prevenção de doenças cardiovasculares e a adoção de bons hábitos para manter a saúde. Inicialmente, foram feitas algumas intervenções com o propósito de sensibilização do público em estações de metrô, em que nutricionistas mediam a circunferência abdominal, calculavam o IMC das pessoas e distribuíam cartilhas com dicas de hábitos saudáveis. Também foram contratados alguns atores para circular por determinados pontos das cidades, acompanhados por um coração gigante, mostrando ao público como algumas atitudes prejudicam o órgão e dando algumas sugestões de atitudes que ajudariam a mantê-lo saudável. Por fim, foi elaborado um web site, no qual podem ser identificados uma aba referente às dicas de alimentação e atividades físicas, uma aba na qual o público pode tirar dúvidas com um cardiologista, uma aba na qual as pessoas podem registrar histórias próprias ou sobre conhecidos que tenham passado por algum problema cardiovascular, um blog com sugestões de receitas saudáveis, uma aba que mostra estatísticas que indicam a necessidade de adoção de hábitos simples e saudáveis e uma aba na qual as pessoas manifestam, por escrito, o modo como se imaginam dali a dez anos.

As ações supracitadas trazem elementos do marketing social, uma vez que buscam modificar comportamentos de determinados públicos em benefício deles e da sociedade. No caso da Iniciativa 1 , esperase que as pessoas desenvolvam um novo comportamento, que é o de levar até as estações instaladas nas lojas do Grupo Y os produtos que podem ser reciclados. Em relação à Iniciativa 2, tem-se o exemplo de disseminação de um novo comportamento relacionado aos hábitos de higiene. Já na Iniciativa 3 , pressupõe-se tanto a modificação de hábitos já existentes quanto a criação de novos hábitos com vistas a prevenir doenças cardíacas. Há diversas maneiras pelas quais o público pode proceder para apoiar as iniciativas, conforme será exposto 
nos resultados desta pesquisa. No que diz respeito à coleta de dados, os seguintes métodos foram utilizados para cada iniciativa:

$\$$ Iniciativa 2 : pesquisa documental (material de sites) e busca de registros em arquivos dos parceiros (coordenadores de paróquia e de diocese); entrevistas (público-alvo e voluntários da ONG K ) e observação;

$\S$ Iniciativa 1 : pesquisa documental (material de sites); entrevistas (público pretendido e colaboradores de cooperativas) e observação;

$\S$ Iniciativa 3 : pesquisa documental (material de sites) e busca de registros em arquivos; entrevistas (público pretendido e colaboradores do projeto).

Foi elaborado um protocolo para subsidiar a coleta de dados, conforme preconiza Yin (2015) e, visando a manter o foco nos assuntos mais relevantes, optou-se por elaborar definições constitutivas e operacionais de termos frequentemente utilizados neste trabalho (Vieira \& Zouain, 2006). Nesse sentido, seguem as seguintes definições constitutivas e como tais definições foram operacionalizadas:

$§$ Interação: Processo dialógico que pode ser visto como o contato mental, físico ou virtual entre empresa e cliente (Grönroos \& Voima, 2013). A interação foi operacionalizada por meio de informações verbais (textuais) e não verbais (gestuais), coletadas através de entrevistas e observações;

$\S$ Interação direta: Interação caracterizada por processos ativos e dialógicos, nos quais os recursos das empresas e dos clientes interagem. Nesse tipo de interação, os processos são simultâneos e interligados, constituindo o único jeito de ocorrer cocriação de valor (Grönroos \& Voima, 2013). Por apresentar um caráter predominantemente síncrono, a interação direta foi operacionalizada pelo contato direto entre os agentes envolvidos no processo (empresa, público e funcionários);

$\S$ Interação indireta: Refere-se a situações em que o cliente usa ou consome outputs de processos da empresa (como um produto, por exemplo) e, assim, interage com este recurso (Grönroos \& Voima, 2013). A interação indireta foi operacionalizada pelo contato do público com elementos dos projetos, de maneira não simultânea e mediada (ex.: contato do público com cartilhas dos projetos);

$\S$ Valor de uso: Valor determinado por um processo contínuo, que envolve e "enfatiza as experiências do cliente", requerendo que ele utilize o produto ao longo do tempo (Grönroos \& Voima, 2013). O valor de uso foi operacionalizado por meio de dois elementos: i) a adesão ou não do público às ações propostas em cada iniciativa; e ii) sua percepção acerca dos motivos pelos quais participaram ou não das ações;

$\S$ Cocriação de valor: Situação caracterizada pela coprodução e pela geração de valor de uso (Ranjan \& Read, 2014). Também é considerada uma função da interação (Grönroos \& Voima, 2013). A cocriação de valor foi operacionalizada por meio de dois elementos: i) a existência de diálogo; acesso; avaliação de risco e transparência (Prahalad \& Ramaswamy, 2004); e ii) a existência de interações, compartilhamento de conhecimentos e equidade (referentes à dimensão coprodução), bem como experiência, relacionamento e personalização (referentes à dimensão geração do valor de uso) (Ranjan \& Read, 2014).

Foram identificados, por meio da pesquisa bibliográfica, inúmeros artigos em que constam, em alguma parte do texto, a expressão "social marketing" e as expressões "value co-creation" e "value co-creating" e seus equivalentes, também pesquisados em fontes brasileiras. Desse modo, foi possível identificar os principais aspectos a serem observados na coleta de dados, conforme apresentado a seguir.

Primeiramente, foram utilizados os critérios de Andreasen (2002) para qualificar as ações. Essa etapa, contudo, foi feita antes das demais análises, uma vez que consistiu uma atividade necessária à escolha dos casos estudados. Além disso, foram avaliados os aspectos delimitadores da lógica de serviço, que estão além do escopo da cocriação de valor (troca de conhecimentos, bens como meios para prestar serviço, relacionamento e multiplicidade de atores sociais envolvidos), bem como a própria criação e cocriação de valor (quem cria e quem cocria valor, tipo de valor, quantidade e tipos de interação, elementos necessários ao bom funcionamento da cocriação e pilares da cocriação de valor). Por fim, considerando os assuntos mais 
recorrentes nos artigos que relacionam os assuntos de interesse da pesquisa, foram analisados os seguintes aspectos:

$\S$ Público como colaborador;

$\S$ Conversas com a população;

$\S$ Trabalho no contexto das comunidades;

$\S$ Experiências de reforço;

$\S$ Geração de envolvimento com a ação, mostrando sua utilidade para as pessoas;

$\$$ Codescoberta; co-design e coentrega de valor;

$\S$ Desafios ideológicos, de integralidade explicativa e de conformidade ética das ações;

$\S$ Abordagem mais evidente;

$\S$ Experiência de serviço como elemento central;

$\S$ Colaborador como ponto de contato entre a organização e o público;

$\S$ Qualidade do serviço e valor como impulsionadores do comportamento;

$\S$ Público-alvo ativo e não passivo;

$\S$ Recursos organizacionais e do público.

Foram entrevistadas 40 pessoas relacionadas às iniciativas investigadas nesta pesquisa, por meio de entrevista pessoal, telefone ou mensagem eletrônica, de acordo com a disponibilidade dos entrevistados. Neste sentido, foram entrevistadas as seguintes pessoas, de acordo com cada iniciativa investigada:

$\S$ Iniciativa 2 : Coordenador de Relações Institucionais da ONG K da cidade de Curitiba (PR); Coordenadora de Saúde de Rio Pomba (MG); coordenadoras das dioceses de Mariana (MG) e Leopoldina (MG); coordenadoras das paróquias de Rio Pomba (MG) e Ubá (MG); seis líderes (pessoas responsáveis pelas visitas às famílias atendidas pela iniciativa); dez famílias atendidas, totalizando 22 pessoas;

$\$$ Iniciativa 3 : Cardiologista que exerce a função de tirar dúvidas de internautas no web site do projeto ; representantes de dois hospitais especializados em doenças cardiovasculares do estado de São Paulo (SP) ; representantes das empresas responsáveis pela elaboração e pela gestão da iniciativa em São Paulo (SP); quatro cardiologistas Belo Horizonte (MG), Juiz de Fora (MG), Ubá (MG) e Rio Pomba (MG); dois profissionais da área de nutrição de Campinas (SP) e Viçosa (MG); e três pessoas pertencentes ao público pretendido da iniciativa, totalizando quatorze pessoas;

$\S$ Iniciativa 1 : líder da cooperativa de reciclagem (Rio de Janeiro (RJ); membro da cooperativa de reciclagem na cidade do Rio de Janeiro $(\mathrm{RJ})$; dois consumidores expostos ao projeto de destinação dos resíduos do Rio de Janeiro $(\mathrm{RJ})$, totalizando quatro pessoas.

\section{Resultados e Discussões}

A seguir, são apresentadas as ações requeridas por parte do público para que as iniciativas atinjam seus resultados. Algumas delas demandam maior envolvimento e outras são apenas atitudes pontuais.

Iniciativa $1:$ i) assistir ao vídeo de apresentação do projeto; ii) baixar a lista de lojas do Grupo Empresarial Y que tem PEV; e iii) separar os resíduos e levá-los aos pontos de coleta.

Iniciativa $2:$ i) baixar a cartilha com o programa de lavagem das mãos; ii) ensinar uma criança a lavar as mãos com água e sabonete; iii) assistir a um vídeo e compartilhá-lo em redes sociais, mediante a promessa de a empresa de destinar $\mathrm{R} \$ 1,00$ (por compartilhamento) em doações para projetos de saúde e higiene infantil; iv) tornar-se voluntário da ONG K, auxiliando o projeto; $\mathrm{v}$ ) compartilhar o vídeo que recruta jovens voluntários para disseminar mensagens do projeto; e vi) como última ação, busca-se disseminar, entre crianças e adultos, a maneira correta de lavar as mãos com sabonete, fazendo disso um hábito. 
Iniciativa $3:$ i) durante as ações públicas, ser atendido por um membro da equipe, obtendo informações sobre IMC e ouvir dicas sobre alimentação saudável e atividades físicas; ii) ler as informações presentes no site da iniciativa ; iii) enviar perguntas ao cardiologista que atua no site ; iv) registrar no site histórias relacionadas ao coração; v) assistir ao vídeo que apresenta estatísticas relacionadas às doenças cardiovasculares; vi) indicar, de forma escrita, como cada pessoa pretende estar daqui a dez anos; vii) ler o conteúdo do blog vinculado à iniciativa ; e viii) adotar as práticas preventivas relacionadas às doenças cardiovasculares.

Tendo em vista a constatação de que todos os casos analisados podem ser classificados como ações de marketing social (tendo sido esse um critério para selecionar os casos estudados), cabe indicar que as iniciativas diferem entre si em relação a diversos aspectos, sendo o principal deles o tipo de esforço que se espera do público. Esta suposição está de acordo com o pensamento de Weinreich (2011), que indica que tempo e esforço são considerados importantes tipos de custos. Gordon (2012) também menciona a existência de diferentes tipos de custos associados à manutenção do comportamento desejado. Em outras palavras, o "preço" que o indivíduo necessita suportar no processo de mudança de comportamento é maior em alguns casos do que em outros. De acordo com esse critério, é possível classificar as ações segundo seu nível de dificuldade e de esforço requerido para que o comportamento se concretize.

A Iniciativa 1 é apresentada como a de mais fácil implementação, seguida da Iniciativa 2 , cabendo à Iniciativa 3 as maiores dificuldades, principalmente para que os comportamentos requeridos se mantenham ao longo do tempo. A primeira, apesar de demandar ações constantes por parte de seu público , é caracterizada pela simplicidade. No caso da segunda , também é provável que, depois de estabelecido o hábito de lavar as mãos, seja considerado uma ação automática e com nível de dificuldade muito pequeno, pois, conforme explica Duhigg (2012): uma vez que determinadas rotinas são vivenciadas, tornando-se hábitos, elas passam a ser desenvolvidas automaticamente, sem que as pessoas precisem pensar a respeito. Por fim, no caso da Iniciativa 3 , o público necessita, constantemente, estar atento aos comportamentos que podem provocar doenças cardiovasculares, o que requer grande esforço tanto para se alimentar de maneira adequada quanto para cumprir uma rotina de atividades físicas.

\section{Aspectos da cocriação de valor identificados nas iniciativas}

A seguir, são apresentadas algumas constatações acerca dos principais elementos da cocriação de valor presentes na literatura, contrapostos ao que se pode identificar nas iniciativas estudadas.

Funções desempenhadas pelas organizações: nos casos estudados, coube inteiramente às organizações envolvidas a tarefa de elaborar as iniciativas. Não foram identificadas evidências do papel do público quando da elaboração e refinamento das ações que seriam implementadas nas iniciativas. Especialmente no caso da Iniciativa 3 , as organizações envolvidas ficaram responsáveis pelo esclarecimento das dúvidas dos consumidores por intermédio do cardiologista que atuava no site do projeto, pela atualização do blog da iniciativa e pelas ações de sensibilização, nas quais eram disponibilizadas informações sobre o IMC e sobre cuidados com o coração. No caso dos questionamentos feitos ao cardiologista ligado do projeto, as perguntas eram analisadas e selecionadas para ter as respostas divulgadas no site (evitando questionamentos pouco pertinentes ou muito pessoais). Apesar do esforço para manter o foco nas questões de prevenção, o médico que atuava no site da Iniciativa 3 comenta que:

\footnotetext{
"No início foram muitas perguntas, embora a maioria envolvesse situações individuais das pessoas, o que me trouxe um pouco de frustração, uma vez que eu esperava que aproveitassem mais a chance de saber sobre a prevenção das doenças cardiocirculatórias e não foi bem isso que ocorreu... A maior parte das perguntas eram relacionadas a dados pessoais, na maioria das vezes envolvendo dados que deveriam ter sido esclarecidos pelos médicos assistentes dos pacientes... Funcionou assim por cerca de dois anos, mas há alguns meses não recebo novas perguntas [...] " [Cardiologista que atuou no site da Iniciativa 3 ].
} 
Em relação ao web site estar ativo ou não (preocupação indicada pelo próprio médico em seu depoimento), os atores envolvidos não se manifestaram indicando se as perguntas ao cardiologista continuam sendo recebidas ou se esta possibilidade de interação já não é mais proporcionada ao público, apesar de, no site, parecer que a opção continua ativa.

Tipo de interação percebida: no caso da Iniciativa 2 , são identificadas interações diretas entre os integrantes do público e os membros da ONG K (coordenadores, líderes) e também algumas interações indiretas (e que requerem pouco esforço por parte das pessoas), caso do compartilhamento dos vídeos que divulgam a iniciativa. Em relação à Iniciativa 1, podem ser identificadas interações diretas entre os atendentes que trabalham nos pontos de coleta e os consumidores. O orientador do grupo de atendentes (cooperados), questionado sobre a importância das interações para o bom desenvolvimento da iniciativa, afirmou que :

"Contribui com certeza, porque a pessoa que vai doar, vai encontrar uma pessoa ali para poder atender e ela já se sente melhor por isso, pela possibilidade de interagir e ela sabe que tem realmente um projeto acontecendo, não é uma coisa que está abandonada, então, a pessoa está ali uniformizada, tem um treinamento, ela é treinada para atender bem o cliente, receber o material, fazer o procedimento corretamente" [Orientador da equipe de atendentes].

Apesar de se reconhecer que a presença dos atendentes potencializa os resultados da iniciativa pela possibilidade de existirem mais interações diretas, cabe destacar que, durante os períodos de observação da execução da iniciativa, muitos foram os casos em que não havia atendentes nos PEV, o que impossibilitava qualquer interação com o público, minimizando, assim, a possibilidade de as organizações cocriarem valor. Essa constatação foi reforçada por um entrevistado (pessoa que entrega resíduos no PEV - 1) que trabalha próximo a um ponto de entrega e que deposita resíduos periodicamente, que afirmou que ocorre frequentemente de não haver pessoas no local de coleta para atender a quem chega. Outra entrevistada, que também trabalha perto do ponto de entrega e que leva resíduos recicláveis periodicamente ao local, afirmou que:

"De vez em quando, vejo alguém fazendo a separação, mas não tem nenhum tipo de relacionamento. Era bom se tivesse alguém informando. Você pode até confundir, tem que ter alguém para indicar. O vidro, por exemplo, não pode só jogar lá, tem materiais que podem oferecer risco" [Pessoa que entrega resíduos no PEV - 2].

A iniciativa também é desenvolvida por meio de interações indiretas, podendo o consumidor apenas depositar os resíduos nas cabines adequadas, sem necessidade de maior diálogo .

No caso da Iniciativa 3 , ocorreram interações diretas, por exemplo, por meio das açóes públicas e da aba do site destinada a esclarecer dúvidas, e também interações indiretas, por exemplo, pela do conteúdo do site. Em relação às possibilidades de interação, tanto diretas quanto indiretas, uma profissional da área de alimentos que foi entrevistada, afirma que considera a abordagem da iniciativa adequada para atingir resultados positivos em relação à prevenção de doenças cardiovasculares. Ela explica que:

“[...] A internet é um meio de comunicação fácil de utilizar e cada vez mais acessível. Assim, de forma interativa, pessoas que talvez tenham dificuldade de acesso à educação alimentar e orientações médicas podem acessar informações simples que as ensinam e as estimulam a pensar na alimentação e adotar boas práticas, que são associadas diretamente à saúde. Além disso, acho interessante a possibilidade de as pessoas identificarem casos similares aos seus e poderem, assim, perceber que os problemas atingem a muitos e que as experiências práticas de outras pessoas podem ensinar a criar alternativas para viver bem e prevenir doenças através de suas escolhas. Acho incrível o estímulo a se imaginar daqui a dez anos! Faz as pessoas refletir sobre as consequências das suas escolhas hoje e a pensar como estarão no futuro! E falando em futuro, a primeira coisa que todo muito deseja é ter mais anos e com saúde!” [Profissional da área de alimentos e nutrição].

Compartilhamento de conhecimentos: $\mathrm{Na}$ Iniciativa 2 , pode-se identificar que a elaboração da ideia envolveu tanto representantes da Empresa X quanto da Coordenação Nacional da ONG K (mais especificamente o setor de relações institucionais e comunicação). $\mathrm{O}$ trecho a seguir, que relata como se deu o processo de elaboração da cartilha, evidencia essa interação . 
“A cartilha foi produzida pela Empresa X , após reunião comigo e pessoas da área de comunicação da ONG K . A fundamentação teórica do texto foi uma pesquisa da Empresa X que previa o aumento das chances de a criança transformar um ato em hábito com 21 dias de insistência no assunto. De nossa parte, observamos que o material deveria ser voltado para crianças pequenas, portanto com pouco texto, muitas ilustrações e ser abrangente em termos de linguagem para contemplar a diversidade do Brasil. A ideia final resultou em um material estilo gibi, com a inclusão de textos e gravuras, com o apelo de crianças menores receberem o auxílio de irmãos maiores ou de adultos para completar as etapas" [Coordenação de Relações Institucionais da ONG K ].

Já em relação à participação do nível operacional da ONG Ke até mesmo às famílias, não existem evidências de compartilhamento de conhecimentos entre as partes, uma vez que a ideia já foi apresentada com o design previamente definido, como mostra o trecho a seguir.

"Vem direto da Nacional de Curitiba, então... eles [ONG K ] só passam um e-mail para a gente comunicando que vai chegar o material e que é para ser distribuído. Não há nossa participação na elaboração da ideia. Já chega uma coisa mais pronta e aí, para a gente não chegar, não passar direto para os coordenadores de paróquia, o que que a gente faz? Chegou material na Diocese, a gente se senta com esses coordenadores de área e faz uma formação como que vai ser trabalhado esse material na comunidade com as crianças, com as famílias. Aí, apesar que (sic) o material vem bem elaborado e tudo, bem explicado, ainda foi enviada folhinha, tipo um manual, e aquilo ajudou muito" [Coordenadora da Diocese de uma cidade da Zona da Mata Mineira ].

Isso não constituiu, entretanto, um problema, já que os voluntários da ONG K costumam preferir seguir programas já elaborados, cabendo a eles somente a execução das ações.

No caso da Iniciativa 1 , não fica evidente o compartilhamento de conhecimentos, pois essa iniciativa aparenta ter sido elaborada por completo pelas empresas envolvidas e só depois apresentada ao público. Entretanto, considerando que antes de elaborar o projeto completo a Empresa X já desenvolvia uma iniciativa semelhante com seus funcionários (algo que foi mencionado no vídeo de abertura da ideia), é possível depreender que a experiência adquirida com esta etapa pode ter sido uma base para compartilhamento de conhecimentos do público interno com a iniciativa desenvolvida pela empresa. Deixar de ouvir o público pode ocasionar perda de opiniões que contribuiriam para a melhoria dos resultados da iniciativa. Procurando identificar que aspectos poderiam ser modificados para potencializar os benefícios desta iniciativa, os entrevistados foram questionados sobre o que fariam de modo diferente no projeto. Uma entrevistada afirmou que:

“Acho que ali eu vejo que começa a acumular muito lixo, demora a ser recolhido, principalmente quando está fora. O recolhimento tem que ser mais eficiente e tem que ter alguém informando. Tem que ser mais dinâmico, eles estão muito engessados. E eles misturam lixo comum com o restante do material. Eu acho que o lixo comum tem que ficar longe de lá” [Pessoa que entrega resíduos no PEV - 2].

No caso da Iniciativa 3 , a situação mais evidente em que ocorre o compartilhamento de conhecimentos reside na possibilidade de o consumidor registrar seus relatos de experiências no site.

Gordon (2012) argumenta que é necessário avançar na compreensão das circunstâncias nas quais o marketing social atua, de modo a considerar os aspectos do ambiente estrutural que exercem impacto sobre a atividade. Nesse sentido, o compartilhamento de conhecimentos, feito de maneira mais aprofundada, poderia contribuir para o melhor entendimento de tais circunstâncias, de modo a permitir o desenvolvimento de ações mais centradas no público a que se destina.

Equidade: Ao aceitar e incentivar a participação das pessoas como voluntárias da ONG K, pode-se afirmar que a Iniciativa 2 atua, pelo menos parcialmente, de acordo com o princípio da equidade, permitindo aos integrantes da sociedade trabalhar na implementação da ideia. Tal trabalho voluntário pode ser interpretado como o compartilhamento do controle das atividades, propiciando, em partes, equidade na distribuição de tarefas. No caso da Iniciativa 1 , não são observados aspectos de equidade, mas uma clara definição de papéis. Pode-se afirmar que a Iniciativa 3 é parcialmente caracterizada pela equidade, por possibilitar ao consumidor 
contribuir com determinadas atividades (podendo, inclusive, humanizar o conteúdo do site), estando o controle da iniciativa mais concentrado nas organizações.

Experiência: A experiência proporcionada pela Iniciativa 2 , além de divertida e forte em sua capacidade de interagir com o público, apresenta potencial para consolidar o hábito de lavar adequadamente as mãos, sugerindo, inclusive, que as crianças façam o compromisso de incorporar tal hábito em diferentes momentos do dia. Assim, associando elementos tangíveis (como a cartilha, o carimbo e o adesivo) e intangíveis (como a visita dos membros da ONG K e o possível acompanhamento de um adulto que tenha contato frequente com a criança), pode-se identificar a geração de consequências emocionais positivas, tanto para o público adulto, que terá em mente que fez algo pela saúde das crianças, quanto para as próprias crianças, que, desde cedo, terão em mente a importância de fazer algo por sua saúde. Assim, acredita-se que a experiência gerada pela participação tenha consideráveis chances de alterar comportamentos das pessoas.

Em relação à Iniciativa 1 , como é comum no campo do marketing social que muitas vezes trabalha com ideias para fundamentar alterações comportamentais (Fine, 1980; Kotler \& Lee, 2011), além da sensação de o indivíduo contribuir para uma causa em seu benefício e também da sociedade - sensação esta que não necessariamente gera resultados imediatos -, não são identificados outros aspectos da experiência que possam gerar consequências emocionais, gerando valor de uso. No entanto, a sensação de autotransformação pode fazer-se presente por meio da noção que o indivíduo tem de contribuir para um suposto bem .

No caso da Iniciativa 3 , pode-se afirmar que o projeto busca interação empática e emocional com o seu público, tanto pelas ações de sensibilização quanto pelas possibilidades de seu site . Por não haver mecanismos qualitativos de avaliação dos resultados dessa iniciativa, não se pode afirmar que a rápida experiência do público com ela seja suficiente para que sejam incorporados novos hábitos ou que sejam modificados os hábitos já existentes. Isso foi ressaltado por uma entrevistada que conheceu a iniciativa, navegou em algumas partes do site, mas teve dificuldades para praticar muitas das orientações lá previstas.

Às vezes você não coloca em prática... não porque não tenha informação, mas por falta de tempo mesmo. No meu caso, após conhecer o projeto, por falta de tempo, não me ative a ele, mas foi apenas por isso... Só não fiz as atividades por falta de tempo mesmo [Representante do público-alvo - 3].

A mesma entrevistada, entretanto, afirmou que, após verificar os resultados de exames de rotina, modificou alguns hábitos alimentares e iniciou imediatamente a prática de atividades físicas. Este relato está de acordo com o que uma cardiologista comentou:

“Tudo será fácil se a pessoa se dedicar e for decidida a cuidar de sua saúde” [Cardiologista 3].

Relacionamento: A Iniciativa 2 é a que mostra maior potencial de relacionamento com as pessoas, principalmente pelo tempo previsto para o desenvolvimento das atividades e pelo tipo de acompanhamento feito. Há diversas situações em que as famílias são expostas aos ensinamentos sobre a lavagem das mãos ou são lembradas da importância desse ato. Na Iniciativa 1, o relacionamento parece muito simplificado: não se nota a consolidação de um ambiente ativo de comunicação, possivelmente pela simplicidade de serem desempenhados os papéis requeridos do consumidor. No caso da Iniciativa 3 , a experiência das pessoas com a iniciativa pode ser rápida, de modo que se torna mais difícil o desenvolvimento de um relacionamento com o público. Entretanto, as partes mais interativas do site indicam a intenção de a iniciativa se relacionar, ainda que brevemente, com seus interlocutores .

Personalização: As atividades que se espera que o público desenvolva na Iniciativa 2 envolvem uma experiência de compartilhamento de algumas tarefas entre um adulto e uma ou mais crianças e requer acompanhamento em sua execução e envolvimento por parte de todos. Considerando que cada contexto no qual ocorre o relacionamento entre crianças e adultos pode ter características distintas, acredita-se que haja uma perspectiva de singularidade no processo. Contudo, essa perspectiva se limita ao contexto dos adultos e crianças envolvidos, pois há padronização de materiais a serem utilizados e, pelo que foi possível identificar 
nas entrevistas, a abordagem feita pelos voluntários da ONG K para estimular a participação das pessoas é bastante similar.

As atividades previstas para o consumidor na Iniciativa 1 são de simples execução, de modo que não trazem uma perspectiva de singularidade do processo e parecem não depender, a princípio, de características individuais dos consumidores para serem executadas. Na Iniciativa 3 , a possibilidade de personalização se dá por meio das partes do site que permitem maior interação, bem como das intervenções públicas, que identificam o IMC das pessoas e fornecem informações úteis à boa saúde cardiovascular.

A comparação dos casos estudados permite indicar que o fenômeno da cocriação de valor se faz presente nas iniciativas apresentadas, uma vez que muitos de seus aspectos foram identificados nos referidos casos. Cabe destacar, no entanto, que a Iniciativa 2 apresenta mais aspectos da cocriação de valor (provavelmente isso se deva à quantidade de intervenções e ao contato direto e frequente com os voluntários da ONG K ). As iniciativas 3 e 1 apresentam situações propícias à cocriação de valor, principalmente pelas interações que possibilitam; contudo, no caso da Iniciativa 3 , o caráter assíncrono das interações pode, por sua vez, diminuir as possibilidades de cocriar valor. No caso da Iniciativa 1 , apesar dos resultados positivos conquistados até o momento (a iniciativa recebeu os prêmios FGV-EAESP de Responsabilidade Social no Varejo em 2003, Guia de Boa Cidadania Corporativa da revista Exame em 2004 e Marketing Best Sustentabilidade em 2008), pode-se afirmar que a execução da ideia não se dá conforme o planejado, subtraindo, em alguns casos, as oportunidades de interação direta, que é um dos principais fatores da cocriação de valor.

Em relação às abordagens identificadas nas ações, as iniciativas estudadas seguem o mesmo padrão identificado por Truong (2014), que afirma que a maioria dos estudos empíricos utilizados em seu trabalho de revisão de literatura sobre marketing social é focada em iniciativas downstream. No caso da presente pesquisa, a referida abordagem foi predominante, embora também tenham sido identificados indícios da abordagem midstream. A seguir, estão relacionados os princípios delimitadores de cada abordagem, bem como são apresentadas as evidências de campo em relação a cada abordagem.

$\S$ Upstream: Atua em níveis mais básicos da formação do comportamento das pessoas, como a ação da iniciativa privada, da mídia ou da legislação (Andreasen, 2006; Carvalho \& Mazzon, 2015). As iniciativas estudadas não trazem indícios da abordagem upstream. Em alguns casos, fundamentam-se em leis, como a Política Nacional de Resíduos Sólidos, mas não atuam fortemente nos níveis básicos que fundamentam comportamentos.

$\S$ Midstream: Pressupóe que a experiência de serviços, os colaboradores, a qualidade do atendimento e o papel ativo do público pretendido na criação de valor podem influenciar e apoiar os objetivos de mudança de comportamento individual (Luca, Hibbert \& McDonald, 2016). $\mathrm{Na}$ Iniciativa 2 , o acompanhamento por parte da equipe da ONG K auxilia fortemente o alcance dos objetivos de mudança comportamental. As demais iniciativas, quando desenvolvidas tendo como referência interações diretas como a abordagem nas estações de metrô ou o atendimento dos trabalhadores dos PEV podem contribuir mais para a mudança de comportamento, mas não de forma tão intensa quanto o que se verifica na Iniciativa 2 .

$\S$ Downstream: Mais propensa a atuar junto ao próprio público, demandando sua alteração comportamental (Kotler \& Lee, 2011). Esta abordagem foi bastante evidente, principalmente nas iniciativas 1 e 3 e, em menor proporção, aparente na iniciativa 2 ", uma vez que todas procuram modificar comportamentos de seus públicos, variando, entretanto, a quantidade e a qualidade das interaçóes.

\section{CONSIDERAÇÕES FINAIS}

O presente artigo teve como objetivo identificar como a cocriação de valor é abordada em programas de marketing social desenvolvidos por uma empresa privada no Brasil e por seus diversos parceiros. Para tanto, foi feito um estudo multicaso, por meio do qual três iniciativas de interesse da sociedade foram investigadas. 
Foi possível identificar diversos aspectos da cocriação de valor nos casos estudados, especialmente nas etapas de implementação das iniciativas. Destaca-se que a Iniciativa 2 se mostrou mais rica em oportunidades de cocriação de valor.

Embora nos três casos a concepção das ideias tenha-se dado, aparentemente, apenas por parte das organizações envolvidas (sem a participação do público pretendido nesta etapa), o que diminui as possibilidades de serem desenvolvidas ações que tenham mais sentido para o público ou até mesmo aderência à sua realidade, reconhece-se que o modo como as iniciativas foram desenvolvidas permitiu que muitas pessoas fossem beneficiadas por sua participação nas atividades. $O$ fato de as iniciativas estudadas serem abrangentes e de interesse da sociedade, possivelmente, contribuiu para o seu sucesso, mesmo que seus públicos não tenham participado ativamente da concepção das ideias.

Esta pesquisa traz contribuições de âmbito acadêmico e gerencial: Em relação ao aspecto acadêmico, este estudo fez a passagem das definições constitutivas para as operacionais no campo da cocriação de valor, o que, por si só, contribui para a geração de insights em análises futuras. Além disso, considerando os casos estudados, foi possível compreender de que modo a cocriação de valor ocorre em iniciativas de marketing social, tornando mais claro esse processo ainda pouco investigado.

Quando à contribuição gerencial, possibilitada pela acadêmica, as descobertas desta pesquisa podem ajudar, primeiramente, a melhorar as iniciativas estudadas, uma vez que foram identificados aspectos em que podem ser vislumbradas melhorias. Adicionalmente, uma vez que esta pesquisa selecionou a literatura adequada à compreensão do assunto e a operacionalizou de modo mais voltado ao âmbito profissional, foi possível identificar, com base nisso, os principais aspectos da cocriação de valor a serem observados quando da avaliação das iniciativas de marketing social. Além disso, as constatações obtidas nesta pesquisa podem, igualmente, inspirar as organizações a planejar investimentos em iniciativas que visem a contribuir para a melhoria do bem-estar social e fazê-lo considerando os elementos do marketing social e da cocriação de valor, principalmente privilegiando as interações diretas como meio de otimizar seus resultados. Em resumo, a análise desenvolvida nesta pesquisa colabora para nortear ações do mercado, mostrando no que podem ser melhorados os projetos estudados, além de auxiliar outras organizações que queiram avaliar seus projetos por meio de critérios relacionados com a cocriação de valor.

Considerando que toda pesquisa tem limitações, cabe indicar que, especificamente em relação à Iniciativa 1 , mesmo após inúmeras visitas aos PEV, foi possível entrevistar poucas pessoas pertencentes ao públicoda iniciativa, uma vez que a movimentação de pessoas no local é muito limitada, o que indica que tais pontos de entrega apresentam potencial para gerar mais resultados, especialmente se melhor divulgados (essa premissa foi indicada por alguns entrevistados). Outra limitação presumida deste estudo refere-se à possibilidade de os participantes da Iniciativa 2 terem se comportado de maneira diferente do que fariam caso não estivessem sendo observados. Em relação ao escopo da pesquisa, embora tenha sido apresentada uma passagem das definições constitutivas para as operacionais e que este trabalho por si só constitua uma contribuição para o campo acadêmico, novas investigações são necessárias para consolidar as definições e seu potencial de aplicação em pesquisas empíricas. É possível indicar, por fim, outros caminhos para pesquisas futuras.

Uma vez que o design das iniciativas estudadas pareceu não considerar fortemente a participação dos beneficiários das ações, sugere-se identificar iniciativas do âmbito do marketing social que tenham sido elaboradas de maneira colaborativa com os beneficiários, a fim de estabelecer comparações que mostrem os limites e as potencialidades da cocriação nesse processo.

Pesquisas que considerem a visão de outros atores estratégicos podem ser úteis para compreender as intenções referentes ao uso dos elementos da cocriação de valor, identificando, por exemplo, se são observados melhores resultados das ações com a utilização dos elementos da cocriação do que sem eles.

Considerando a identificação de que as iniciativas estudadas partem de abordagens predominantemente downstream, é útil investigar os motivos que levam a esta aparente tendência, uma vez que diversos 
autores defendem, na atualidade, que o marketing social, segundo uma abordagem upstream, pode alcançar resultados mais abrangentes.

Tendo em vista a identificação de diversos elementos característicos da cocriação de valor nas iniciativas estudadas e que isso parece auxiliar o curso das ações propostas, sugere-se a realização de experimentos que permitam comparar programas de marketing social que contenham elementos da cocriação de valor com programas que não englobem tais conceitos .

\section{ReFERÊNCIAS BibLIOGRÁFiCAS}

Andreasen, A. R. (2002). Ética e Marketing Social: como conciliar os interesses do cliente, da empresa e da sociedade numa ação de marketing (1o ed). São Paulo: Futura.

Andreasen, A. R. (2003). The Life Trajectory of Social Marketing Some implications. Marketing Theory, 3(3), 293303.

Andreasen, A. R. (2006). Social marketing in the 21st century (1o ed). California: Sage.

Bharti, K., Rajat Agrawal, \& Sharma, V. (2015). Value co-creation: Literature review and proposed conceptual framework. International Journal of Market Research, 57(4), 571-604.

Bowman, C., \& Ambrosini, V. (2000). Value Creation Versus Value Capture: Towards a Coherent Definition of Value in Strategy. British Journal of Management, 11(1), 1-15.

Carvalho, H. C., \& Mazzon, J. A. (2015). A better life is possible: the ultimate purpose of social marketing. Journal of Social Marketing, 5(2), 169-186.

Costa, M. F. da, \& Matos, C. R. B. de F. (2009). O marketing social como uma ferramenta de promoção para instituição filantrópica. Administração Pública e Gestão Social, 1(1), 67-87.

Desai, D. (2009). Role of Relationship Management and Value Co-Creation in Social Marketing. Social Marketing Quarterly, 15(4), 112-125.

Dietrich, T., Rundle-Thiele, S., Schuster, L., \& Connor, J. (2016). Co-designing social marketing programs. Journal of Social Marketing, 6(1), 41-61.

Domegan, C., Collins, K., Stead, M., McHugh, P., \& Hughes, T. (2013). Value co-creation in social marketing: functional or fanciful? Journal of Social Marketing, 3(3), 239-256.

Duhigg, C. (2012). O poder do hábito: por que fazemos o que fazemos na vida e nos negócios. Rio de Janeiro: Objetiva.

Fine, S. H. (1980). Toward a Theory of Segmentation by Objectives in Social Marketing. Journal of Consumer Research, 7(1), 1-13.

Gordon, R. (2012) Re-thinking and re-tooling the social marketing mix. Australasian Marketing Journal 20, 122-126.

Grönroos, C., \& Voima, P. (2013). Critical service logic: making sense of value creation and co-creation. Journal of the Academy of Marketing Science, 41(2), 133-150. https://doi.org/10.1007/s1 1747-012-0308-3

Higuchi, A. K., \& Veiga, R. T. (2015). O processo de cocriação de valor no Marketing Social: uma análise do ponto de vista da Lógica Dominada pelo Serviço. In XXXIX Encontro da ANPAD. Belo Horizonte.

iSMA, ESMA, AASM. (2013). A Consensus Definition of Social Marketing - On Social Marketing and Social Change. Recuperado 15 de março de 2016, de http://socialmarketing.blogs.com/r_craiig_lefebvres_social/2013/10/aconsensus-definition-of-social-marketing.html

Khajeh, E., Dabestani, R., \& Fathi, S. (2015). The role of upstream and downstream social marketing in electricity consumption management. International Journal of Business Innovation and Research, 9(3), 311-328.

Kotler, P. (1972). A Generic Concept of Marketing. Journal of Marketing, 36(2), 46-54.

Kotler, P., \& Lee, N. (2011). Marketing Social: influenciando comportamentos para o bem (3o ed). Porto Alegre: Bookman.

Lefebvre, R. C. (2012). Transformative social marketing: Co-creating the social marketing discipline and brand. Journal of Social Marketing, 2(2), 118-129. https://doi.org/10.1108/20426761211243955 
Luca, N. R.; Hibbert, S. \& McDonald, R. (2016). Midstream value creation in social marketing. Journal of Marketing Management. 32(11), 1145-1173.

Lusch, R. F., \& Vargo, S. L. (2012). The forum on markets and marketing (FMM) Advancing service-dominant logic. Marketing Theory, 12(2), 193-199.

Madill, J., \& Ziegler, R. (2012). Marketing social missions-adopting social marketing for social entrepreneurship? A conceptual analysis and case study. International Journal of Nonprofit and Voluntary Sector Marketing, 17(4), 341-351.

Prahalad, C. K., \& Ramaswamy, V. (2004). Co-creation experiences: The next practice in value creation. Journal of Interactive Marketing, 18(3), 5-14.

Ranjan, K. R., \& Read, S. (2014). Value co-creation: concept and measurement. Journal of the Academy of Marketing Science, 1-26.

Russell-Bennett, R., Previte, J., \& Zainuddin, N. (2009). Conceptualising value creation for social change management. Australasian Marketing Journal (AMJ), 17(4), 211-218.

Russell-Bennett, R., Wood, M., \& Previte, J. (2013). Fresh ideas: services thinking for social marketing. Journal of Social Marketing, 3(3), 223-238.

Saunders, S. G., Barrington, D. J., \& Sridharan, S. (2015). Redefining social marketing: beyond behavioural change. Journal of Social Marketing, 5(2), 160-168.

Shostack, G. L. (1977). Breaking Free from Product Marketing. Journal of Marketing, 41(2), 73.

Stead, M., Gordon, R., Angus, K., \& McDermott, L. (2007). A systematic review of social marketing effectiveness. Health Education, 107(2), 126-191.

Truong, V. D. (2014). Social Marketing: A Systematic Review of Research 1998-2012. Social Marketing Quarterly, 20(1), 15-34.

Vargo, S. L., \& Lusch, R. F. (2004). Evolving to a New Dominant Logic for Marketing. Journal of Marketing, 68(1), $1-17$.

Vargo, S. L., \& Lusch, R. F. (2008). Service-dominant logic: continuing the evolution. Journal of the Academy of Marketing Science, 36(1), 1-10. https://doi.org/10.1007/s11747-007-0069-6

Vargo, S. L., \& Lusch, R. F. (2016). Institutions and axioms: an extension and update of service-dominant logic. Journal of the Academy of Marketing Science, 44(1), 5-23.

Vargo, S. L., Maglio, P. P., \& Akaka, M. A. (2008). On value and value co-creation: A service systems and service logic perspective. European Management Journal, 26(3), 145-152.

Vieira, M. M. F., \& Zouain, D. M. (Orgs.). (2006). Pesquisa Qualitativa em Administração (2o ed). Rio de Janeiro: Editora FGV.

Weinreich, N. K. (2011). Hands-on Social Marketing: a step-by-step guide to designing change for good (2o ed). California: Sage Publications.

Yin, R. K. (2015). Estudo de caso: planejamento e métodos (5o ed). Porto Alegre: Bookman.

Zainuddin, N. (2013). Examining the impact of experience on value in social marketing. Journal of Social Marketing, $3(3), 257-274$.

\section{Notas}

i Para conhecer a trajetória a partir da qual a lógica sofreu reformulações, recomenda-se ler Vargo e Lusch $(2008 ; 2016)$ e Lusch e Vargo (2012).

\section{BY-NC-ND}

